\title{
Relationship between Participation Motivation and Psychological Well-being of Marine Leisure Sports Participants
}

\author{
Young-Hoon Kwon, Lecturer, Dept. of Marine Sports, Hanseo University, Seosan 31962, Korea. \\ *Chun-Ho Yang, Professor, Dept. of Marine Sports, Hanseo University, Seosan 31962, Korea, \\ healthyang@hanseo.ac.kr \\ *Corresponding Author
}

\begin{abstract}
This study aims to find out the psychological wellbeing relationship and motivation of participants in marine sports. The subjects to the study were the population of participants who regularly participate in marine leisure sports. For sampling, a random sampling method was used. The survey was answered using the self-evaluation method through a questionnaire. Data processing was obtained by statistical processing of 341 questionnaires out of all the sincere data among the questionnaires. Through data processing, we got the following results. First, the internal motivation of marine leisure sports participants was positively correlated with all factors of psychological well-being. Second, all factors of participation motivation of marine leisure sports participants were found to have positive effects on selfacceptance and positive interpersonal relationships. Research has also shown that voluntary and continuous participation in sports activities will increase levels of psychological well-being. In particular, the study showed that the motivation for participants in marine sports is an important factor that has a beneficial influence on psychological happiness. This suggests that participation motivation of marine sports participants can positively contribute to the improvement of quality of life by contributing to positive emotional purification.
\end{abstract}

Keywords: Marine Leisure Sports, Internal Motivation, External Motivation, Motiveless, Psychological Well-being.

Received: 04.12.2020 $\quad$ Accepted: 15.01.2021 $\quad$ Published: 07.02.2021

\section{INTRODUCTION}

In preparation for the era of marine sports, the government of the Republic of Korea is pursuing plans for water experience tourism, water friendly culture parks, waterside ecology parks, and waterside fishing parks by coastal regions and the four major river regions. The creation of such spaces for marine sports provides the public with opportunities to experience marine leisure sports naturally. As interest in marine sports has recently increased due to changes in the waterfront environments, users in the central inland area have increased their ownership of leisure boats and other equipment to enjoy marine leisure sports. In addition, interest in marine leisure sports has been increasing, with this interest centered on clubs.

The reason that marine leisure sports have become popular in Korea is because of an increased focus on psychological well-being, which is achieved not only through personal health and fitness, but also through smooth interpersonal relationships in social life. Sports provide energy and enjoyment, reduce tension and stress, and increase health and happiness [1]. In particular, waterskiing, windsurfing, wakeboarding, and scuba diving are representative marine leisure sports, and they are attractive sports activities that provide a sense of challenge and enjoyment while allowing one to maintain harmony with nature [2]. Therefore, marine leisure sports bring the mystery and curiosity of nature to modern people while also bringing fun and happiness to not only individuals but also families, colleagues, and couples.

Recently, research on marine sports participants has been conducted on various psychological factors such as motivation, interest, characteristics, habits, interests, participation, and satisfaction. These various marine sports-related studies suggest that participation in marine sports can improve the quality of life of modern people, thereby increasing individual satisfaction and thereby increasing their contribution to family and society. Participation motivation is a factor that explains why people participate in sports activities. The issue of participation motivation is considered an important factor because it not only helps people understand and analyze why they participate in sports, but also helps them understand the results of sports participation.

Motivation in sports participation is an intrinsic driving force that induces action, and it is a very important factor for understanding the exercise behavior related to the needs of people. In general, the 
main motivations for participating in exercise include health promotion, body shape maintenance, weight control, personal appearance improvement, technique learning, psychological happiness, and enjoyment. The main factors influencing participation motivation are defined as perceived psychological well-being of sports as well as participation satisfaction and leisure satisfaction of sports participants. Of the concepts related to psychological well-being through sports activities, wellbeing can be conceptualized in terms of satisfaction, subjective wellbeing, and happiness [3], and it is also used synonymously with life satisfaction or welfare. Psychological well-being helps individuals improve their emotional stability and confidence [4]. In particular, motivation to participate in sports activities has been found to have a positive effect on individual psychological well-being [5]. Therefore, it is also meaningful to find the importance of marine sports participants by analyzing their motivation to participate in marine sports activities and studying the degree of psychological happiness according to the results of their participation.

\section{Methods}

\subsection{Subjects}

Table 1 General contents of study subjects

\begin{tabular}{llll}
\hline & Division & People (n) & Percentage (\%) \\
\hline \multirow{2}{*}{ Gender } & Male & 182 & 53.4 \\
& Female & 159 & 46.6 \\
\multirow{4}{*}{ Age } & $20 \mathrm{~s}$ & 62 & 18.3 \\
& $30 \mathrm{~s}$ & 117 & 34.3 \\
& $40 \mathrm{~s}$ & 107 & 31.4 \\
& $50 \mathrm{~s}$ and over & 55 & 16.0 \\
& Scuba diving & 54 & 15.8 \\
\multirow{4}{*}{ Participation events } & Windsurfing & 115 & 33.6 \\
& Waterskiing & 103 & 30.1 \\
& Yacht & 35 & 10.3 \\
& Leisure canoe & 34 & 10.2 \\
\hline
\end{tabular}

The subjects of this study were a population of participants who regularly participate in marine leisure sports. For sampling, a random sampling method was used. The survey was answered using the self-evaluation method through a questionnaire. [Table 1] is the result of 341 statistical treatments of faithful questionnaire data, representing the typical characteristics of the study participants.

\subsection{Tools}

\subsubsection{Participation motivation}

The participation motivation questionnaire used in this study was based on the Leisure Intrinsic Motivation (LIM) of [6], and questions used by [7]. were modified according to the purpose of this study before being used. The measurement method of each item was composed of Likert scales (disagree 1 point' to agree 5 points).

\subsubsection{Psychological well-being}

The psychological well-being questionnaire used in this study was based on the Psychological WellBeing Scale (PWBS) of [8], and questions used by [9] . were modified and used according to the purpose of this study. The measurement method of each item was composed of Likert (disagree 1 point' to agree 5 points).

\subsection{Validity and Reliability}

The main component analysis of exploratory factorial analysis was used to validate the survey tool. 
Barimax was used directly in the church system for the simplification of the component structure. Cronbach's $\alpha$ coefficient according to the internal consistency criteria was used to verify the reliability of the survey tool.

\subsubsection{Participation motivation}

Table 2 Results of validity and reliability analysis of participation motivation

\begin{tabular}{|c|c|c|c|c|}
\hline Variable & Internal motivation & $\begin{array}{r}\text { External } \\
\text { motivation }\end{array}$ & Motiveless & $\mathrm{h}^{2}$ \\
\hline Q 03 & .830 & .129 & .156 & .617 \\
\hline Q 04 & .824 & .110 & .071 & .673 \\
\hline Q 02 & .816 & .090 & -.009 & .730 \\
\hline Q 05 & .763 & .107 & .154 & .697 \\
\hline Q 01 & .762 & .191 & .020 & .617 \\
\hline Q 07 & .150 & .829 & .030 & .603 \\
\hline Q 08 & .029 & .812 & .239 & .710 \\
\hline Q 09 & .168 & .750 & .225 & .717 \\
\hline Q 06 & .205 & .718 & .212 & .641 \\
\hline Q 10 & .130 & .565 & .350 & .659 \\
\hline Q 13 & .083 & .118 & .813 & .643 \\
\hline Q 12 & .006 & .325 & .709 & .609 \\
\hline Q 11 & .158 & .239 & .679 & .682 \\
\hline Eigenvalue & 4.843 & 2.355 & 1.100 & \\
\hline Dispersion\% & 37.253 & 18.119 & 8.462 & \\
\hline Cumulative\% & 37.253 & 55.372 & 63.834 & \\
\hline Reliability & .788 & .796 & .808 & \\
\hline
\end{tabular}

$\mathrm{KMO}=.869, \chi^{2}=1833.486, \mathrm{df}=78, p=.001$

The Bartlett unit matrix of participation motivation was 1833.486, its significance probability was .001 , and its KMO index was .869. As a result of the factor analysis of 13 questions, participation motivation showed that three factors were extracted, and these accounted for $63.8 \%$ of the total variance. The factor loadings of participation motivation were as follows: internal motivation (.762 .830), external motivation (.565 .829), and motiveless (.679 .813). The reliability values of participation motivation were as follows: internal motivation (.788), external motivation (.796), and motiveless (.808).

\subsubsection{Psychological well-being}

Table 3 Results of validity and reliability analysis of psychological well-being

\begin{tabular}{|c|c|c|c|c|c|c|c|}
\hline Variable & Self-Accept & $\begin{array}{l}\text { Positive- } \\
\text { Relation }\end{array}$ & Purpose Life & $\begin{array}{l}\text { Environmenta } \\
1\end{array}$ & Personal-GT & Autonomy & $h^{2}$ \\
\hline Q 07 & .767 & .006 & .156 & -.002 & .209 & .126 & .608 \\
\hline Q 06 & .720 & .094 & .180 & .093 & .156 & .158 & .642 \\
\hline Q 08 & .687 & .101 & .112 & -.053 & .114 & .132 & .659 \\
\hline Q 10 & .633 & .216 & -.078 & .063 & .147 & .082 & .666 \\
\hline Q 09 & .621 & .293 & .169 & -.026 & .108 & .227 & .618 \\
\hline Q 23 & .122 & .741 & .210 & .028 & .110 & .078 & .673 \\
\hline Q 26 & .141 & .695 & .292 & .103 & .048 & .185 & .528 \\
\hline Q 27 & .191 & .681 & .124 & -.155 & .211 & .131 & .564 \\
\hline Q 24 & .110 & .669 & .217 & .131 & .066 & .086 & .586 \\
\hline Q 25 & .140 & .553 & .394 & .204 & .099 & .040 & .630 \\
\hline Q 05 & .039 & .206 & .751 & .111 & -.008 & .213 & .685 \\
\hline Q 04 & .130 & .224 & .744 & .114 & .148 & -.063 & .730 \\
\hline Q 03 & .221 & .281 & .676 & .227 & -.027 & .065 & .603 \\
\hline Q 01 & .107 & .329 & .672 & .105 & .157 & -.042 & .658 \\
\hline Q 20 & .051 & .080 & .110 & .808 & .027 & -.160 & .587 \\
\hline Q 22 & -.005 & .062 & .095 & .787 & -.110 & .159 & .606 \\
\hline Q 19 & .031 & .129 & .064 & .786 & -.008 & -.171 & .588 \\
\hline Q 21 & -.029 & -.075 & .212 & .683 & -.007 & .212 & .668 \\
\hline
\end{tabular}




\begin{tabular}{|c|c|c|c|c|c|c|c|}
\hline Q 13 & .074 & .141 & .048 & -.109 & .818 & .144 & .700 \\
\hline Q 12 & .279 & .157 & .118 & .054 & .714 & .235 & .564 \\
\hline Q 11 & .305 & .122 & .093 & .007 & .675 & .240 & .669 \\
\hline Q 14 & .251 & .065 & .044 & -.057 & .612 & .394 & .627 \\
\hline Q 15 & .169 & .044 & .158 & -.026 & .189 & .753 & .536 \\
\hline Q 16 & .091 & .131 & -.063 & .113 & .245 & .696 & .533 \\
\hline Q 17 & .307 & .154 & .131 & -.154 & .273 & .610 & .636 \\
\hline Q 18 & .350 & .253 & -.040 & .052 & .206 & .596 & .601 \\
\hline Eigenvalue & 7.422 & 3.356 & 1.892 & 1.354 & 1.040 & 1.001 & \\
\hline Dispersion\% & 28.546 & 12.907 & 7.277 & 5.208 & 4.000 & 3.851 & \\
\hline$\%$ Cumulative & 28.546 & 41.452 & 48.730 & 53.938 & 57.937 & 61.788 & \\
\hline Reliability & .786 & .785 & .792 & .855 & .802 & .800 & \\
\hline
\end{tabular}

$\mathrm{KMO}=.883, \chi^{2}=3663.836, \mathrm{df}=325, p=.001$

The Bartlett unit matrix of psychological well-being was 3663.836, its significance probability was .001, and its KMO index was .883. For psychological well-being, a factor analysis of 26 questions found that 6 factors were extracted, and these 6 factors accounted for about $61.8 \%$ of the total variance. The factor loadings of psychological well-being were as follows: acceptance (.621 .767), positive interpersonal relationships (.553 .741), purpose of life (.672 .751), environmental dominance (.683 .808), personal growth (.612 .818), and autonomy (.596 .753). The reliability values of psychological well-being were as follows: self-acceptance (.786), positive interpersonal relationships (.785), purpose of life (.792), environmental dominance (.855), personal growth (.802), and autonomy (.800).

\subsection{Data Processing}

The data collected in this study was verified using the SPSS statistical program using frequency analysis, factor analysis, and reliability analysis. The results of the variables were correlated, multiple regression analysis, and the significance level was $\alpha=.05$.

\section{Results}

3.1. Correlation Motivation and Participation Relationship Between Psychological Well-Being of Participants in Marine

Table 4 Between and psychological well-being and participation motivation

\begin{tabular}{|c|c|c|c|c|c|c|c|c|c|}
\hline Variable & $\mathrm{A}$ & B & $\mathrm{C}$ & $\mathrm{D}$ & $E$ & $\mathrm{~F}$ & G & $\mathrm{H}$ & I \\
\hline $\mathrm{A}$ & - & & & & & & & & \\
\hline B & $.338^{* * *}$ & - & & & & & & & \\
\hline $\mathrm{C}$ & $.238^{* * *}$ & $.534^{* * *}$ & - & & & & & & \\
\hline D & $.423^{* * *}$ & $.680 * * *$ & $.614^{* * *}$ & - & & & & & \\
\hline $\mathrm{E}$ & $.609 * * *$ & $.409 * * *$ & $.328^{* * *}$ & $.448^{* * *}$ & - & & & & \\
\hline $\mathrm{F}$ & $.692^{* * *}$ & $.311^{* * *}$ & $.198^{* * *}$ & $.360 * * *$ & $.623^{* * *}$ & - & & & \\
\hline G & $.344^{* * *}$ & -.057 & -.060 & .067 & $.196^{* * *}$ & $.319 * * *$ & - & & \\
\hline $\mathrm{H}$ & $.266^{* * *}$ & $.552^{* * *}$ & $.381^{* * *}$ & $.535^{* * *}$ & $.384^{* * *}$ & $.260^{* * *}$ & .029 & - & \\
\hline I & $.240^{* * *}$ & $.506^{* * *}$ & $.470^{* * *}$ & $.538^{* * *}$ & $.383^{* * *}$ & $.251^{* * *}$ & .012 & $.625^{* * *}$ & - \\
\hline
\end{tabular}

A: internal motivation, B: external motivation, C: motiveless, D: self-acceptance

E: positive interpersonal relationships, F: purpose of life, G: environmental dominance

H: personal growth, I: autonomy Sports

For the correlations between participation motivation and psychological well-being of marine leisure sports participants, internal motivation, purpose of life $(r=.692)$, positive interpersonal relationships ( $\mathrm{r}=.609)$, self-acceptance $(\mathrm{r}=.423)$, environmental dominance $(\mathrm{r}=.344)$, personal growth $(\mathrm{r}=.266)$, and autonomy ( $\mathrm{r}=.240)$ showed statistically significant positive correlations $(\mathrm{p}<.001)$. For external motivation, self-acceptance $(\mathrm{r}=.680)$, personal growth $(\mathrm{r}=.552)$, autonomy $(\mathrm{r}=.506)$, positive 
interpersonal relationships $(\mathrm{r}=.409)$, and purpose of life $(\mathrm{r}=.311)$ showed statistically significant positive correlations $(\mathrm{p}<.001)$. For motiveless, self-acceptance $(\mathrm{r}=.614)$, autonomy $(\mathrm{r}=.470)$, personal growth $(\mathrm{r}=.381)$, positive interpersonal relationships $(\mathrm{r}=.328)$, and purpose of life $(\mathrm{r}=.198)$ showed statistically significant positive correlations $(\mathrm{p}<.001)$.

\subsection{Effect of Motivation Participation of Marine Sports Participants on Psychological Well-Being}

\subsubsection{Effects of participation motivation on self-acceptance}

Table 5 Participation motivation and self-acceptance

\begin{tabular}{lllllll}
\hline & $\mathrm{B}$ & $\mathrm{SE}$ & $\beta$ & $t$ & Tolerance & VIF \\
\hline Constant & .289 & .165 & & 1.750 & & \\
Internal motivation & .146 & .028 & .196 & $5.224^{* * *}$ & .881 & 1.135 \\
External motivation & .436 & .043 & .434 & $10.087^{* * *}$ & .667 & 1.499 \\
Motiveless & .326 & .040 & .336 & $8.051^{* * *}$ & .711 & 1.407 \\
\hline \multicolumn{2}{r}{$=157.682^{* * *}, \mathrm{R}^{2}=.584$, Modified $\mathrm{R}^{2}=.580$} & & & & \\
\hline$* * * p<.001$ & & & &
\end{tabular}

[Table 5] is the effect of participation motivation on self-acceptance was significance level $(\mathrm{F}=157.682$, $\mathrm{p}<.001)$, and the influence was about 58.4\% $\left(\mathrm{R}^{2}=.584\right)$ of the total variance. The results of Beta values for internal motivations for self-acceptance have been shown to have a positive effect on motivation for participation $(\beta=.196, \mathrm{p}<.001)$, external motivation $(\beta=.434, \mathrm{p}<.001)$, and motiveless $(\beta=.336, \mathrm{p}<.001)$.

\subsubsection{Effects of participation motivation on positive interpersonal relationships}

Table 6 Participation motivation and positive interpersonal relationships

\begin{tabular}{lllllll}
\hline & $\mathrm{B}$ & $\mathrm{SE}$ & $\beta$ & $t$ & Tolerance & VIF \\
\hline \multicolumn{1}{c}{ Constant } & .889 & .219 & & $4.056^{* * *}$ & & \\
Internal motivation & .439 & .037 & .524 & $11.910^{* * *}$ & .881 & 1.135 \\
External motivation & .195 & .057 & .171 & $3.390^{* * *}$ & .667 & 1.499 \\
Motiveless & .123 & .054 & .112 & $2.287^{* * *}$ & .711 & 1.407 \\
\hline
\end{tabular}

$\mathrm{F}=83.239 * * *, \mathrm{R}^{2}=.426$, Modified $\mathrm{R}^{2}=.421$

*** $p<.001$

As shown in [Table 6], the effect of participation motivation on positive interpersonal relationships was statistically significant $(\mathrm{F}=83.239, \mathrm{p}<.001)$, and the influence was about $42.6 \%\left(\mathrm{R}^{2}=.426\right)$ of the total variance. Internal motivation $(\beta=.524, \mathrm{p}<001)$ for the relative impact Beta value of positive interpersonal participation motivation, and external motivation $(\beta=.171, \mathrm{p}<001)$, and motiveless $(\beta=.112, \mathrm{p}<.05) \mathrm{had}$ a positive effect.

\subsubsection{Effects of participation motivation on purpose of life}

Table 7 Participation motivation and purpose of life

\begin{tabular}{lllllll}
\hline & $\mathrm{B}$ & $\mathrm{SE}$ & $\beta$ & $t$ & Tolerance & VIF \\
\hline \multicolumn{1}{c}{ Constant } & .776 & .234 & & $3.323^{* * *}$ & & \\
Internal motivation & .626 & .039 & .663 & $15.906^{* * *}$ & .881 & 1.135 \\
External motivation & .117 & .061 & .092 & 1.915 & .667 & 1.499 \\
Motiveless & -.010 & .057 & -.008 & -.182 & .711 & 1.407 \\
\hline $\mathrm{F}=105.794^{* * *}, \mathrm{R}^{2}=.485$, Modified $\mathrm{R}^{2}=.480$ & & & &
\end{tabular}

As shown in [Table 7], the effect of participation motivation on purpose of life was statistically significant $(\mathrm{F}=105.794, \mathrm{p}<.001)$, and the influence was about $48.5 \%$ ( $\mathrm{R} 2=.485)$ of the total variance. The results of Beta values for internal motivations for on purpose of life have been shown to have a positive effect in internal motivation for participation $(\beta=.663, \mathrm{p}<.001)$. 


\subsubsection{Effects of participation motivation on environmental dominance}

Table 8 Participation motivation and environmental dominance

\begin{tabular}{lllllll}
\hline & $\mathrm{B}$ & $\mathrm{SE}$ & $\beta$ & $t$ & Tolerance & VIF \\
\hline Constant & 2.474 & .346 & & $7.150^{* * *}$ & & \\
Internal motivation & .453 & .058 & .415 & $7.779^{* * *}$ & .881 & 1.135 \\
External motivation & .234 & .091 & .158 & $2.577^{* * *}$ & .667 & 1.499 \\
Motiveless & -.107 & .085 & .075 & -1.260 & .711 & 1.407 \\
\hline
\end{tabular}

$\mathrm{F}=20.774^{* * *}, \mathrm{R}^{2}=.156$, Modified $\mathrm{R}^{2}=.149$

*** $p<.001$

As shown in [Table 8], the effect of participation motivation on environmental dominance was statistically significant $(\mathrm{F}=20.774, \mathrm{p}<.001)$, and the influence was about $15.6 \%\left(\mathrm{R}^{2}=.156\right)$ of the total variance. Beta value of the impact of motivation to participate on environmental dominance, there were positive influences in internal motivation $(\beta=.415, \mathrm{p}<.001)$ and external motivation $(\beta=.158, \mathrm{p}<.001)$.

\subsubsection{Effects of participation motivation on personal growth}

Table 9 Participation motivation and personal growth

\begin{tabular}{|c|c|c|c|c|c|c|}
\hline & $\mathrm{B}$ & SE & $\beta$ & $t$ & Tolerance & VIF \\
\hline Constant & 1.194 & .225 & & $5.297 * * *$ & & \\
\hline Internal motivation & .065 & .038 & .082 & 1.721 & .881 & 1.135 \\
\hline External motivation & .499 & .059 & .464 & $8.438^{* * *}$ & .667 & 1.499 \\
\hline Motiveless & .119 & .055 & .114 & $2.142^{*}$ & .711 & 1.407 \\
\hline \multicolumn{7}{|c|}{$\mathrm{F}=53.024^{* * *}, \mathrm{R}^{2}=.321$, Modified $\mathrm{R}^{2}=.315$} \\
\hline
\end{tabular}

As shown in [Table 9], the effect of participation motivation on personal growth was statistically significant $(\mathrm{F}=53.204, \mathrm{p}<.001)$, and the influence was about $32.1 \%\left(\mathrm{R}^{2}=.321\right)$ of the total variance. Beta value of the impact of motivation to participate on personal growth, there were positive influences in external motivation $(\beta=.464, p<.001)$ and motiveless $(\beta=.114, p<.05)$.

\subsubsection{Effects of participation motivation on autonomy}

Table 10 Participation motivation and autonomy

\begin{tabular}{|c|c|c|c|c|c|c|}
\hline & $\mathrm{B}$ & SE & $\beta$ & $t$ & Tolerance & VIF \\
\hline Constant & 1.214 & .220 & & $5.297^{* * *}$ & & \\
\hline Internal motivation & .046 & .037 & .060 & 1.241 & .881 & 1.135 \\
\hline External motivation & .354 & .058 & .339 & $6.149 * * *$ & .667 & 1.499 \\
\hline Motiveless & .277 & .054 & .275 & $5.134 * * *$ & .711 & 1.407 \\
\hline
\end{tabular}

As shown in [Table 10], the effect of participation motivation on autonomy was statistically significant $(\mathrm{F}=51.688, \mathrm{p}<.001)$, and the influence was about $31.5 \%\left(\mathrm{R}^{2}=.315\right)$ of the total variance. Beta value of the impact of motivation to participate on autonomy, there were positive influences in external motivation $(\beta=.339, p<.001)$ and motiveless $(\beta=.275, p<.001)$

\section{Discussion}

Recently, there has been a social phenomenon in which ordinary people want to spend their leisure time more pleasantly. To meet these needs, modern people are interested in marine sports, which are exotic and environmentally friendly sports. Therefore, the relationship between motivation and psychological well-being was analyzed for participants in marine leisure sports in this study. The results showed that motivation for participation has a static effect on psychological well-being. In other words, 
the fact that participants in marine leisure sports enjoy marine sports themselves and participate autonomously can be seen as improving the quality of life.

The motivation for participants in marine leisure sports is to generate a constant desire for participation. It can be seen that this desire is not merely a maniac, but rather because it affects satisfaction and happiness in life, that is, well-being. The motivation for participating in marine sports is to have a positive attitude toward oneself, to have a satisfying relationship with others, and to control complex external activity plans well. In particular, this study confirmed that internal motivation allows people to have a sense of purpose and direction in life, and external motivation tries to realize their potential. This suggests the same results as the study[2] that higher motivation for sports participants to participate can not only provide incentives for them to become maniacs, but also increase their satisfaction in life, and the study[1] that people participating in sports programs have a static impact on psychological well-being [3] and others that motivation for sports participation of people with disabilities has a significant impact on psychological well-being.

In addition, it has been revealed that motivation affects self-acceptance of self-indulgence, positive interpersonal relationships showing social relationships, personal growth showing self-development tendencies, and self-determination. affects autonomy, positive interpersonal relationships, personal growth and self-acceptance .In this regard, a study conducted by [10] found that the higher the participation motivation, the more happiness was felt, and it was argued that positive interaction of sports participation motivation was an important variable in psychological well-being. Also, a study of outdoor sports participants [11] found that intrinsic motivational induction based on sporting environmental satisfaction had a beneficial influence on psychological happiness. In addition, research on the impact of motivation on psychological happiness of water sports participants [12] and the study on the relation between motivation and psychological happiness of collegian who voluntarily participate in golf classes [13] showed that motivation to participate has a positive effect. These studies are also consistent with the results of this study, and if sports have a positive impact on human life, teenagers can experience sociality and adventure.

Living sports, a healthy leisure culture of healthy members of society, has been said to represent an opportunity to restore the human relationships that have been weakened in modern society. Therefore, active participation in daily life and physical education will help people spend their daily lives more beneficially. Research has also shown that voluntary and continuous participation in sports activities will increase levels of psychological well-being. In particular, this study showed that participation motivation of marine leisure sports participants is an important factor that has an affirmative influence on psychological happiness. The higher the participation motivation of marine leisure sports participants, the higher their psychological wellbeing and happiness. In other words, the higher the internal motivation, the greater the desire to demonstrate one's ability. When a person has high external motivation, their desire to develop skills increases. This suggests that the participation motivation of marine leisure sports participants can positively contribute to the improvement of quality of life by contributing to positive emotional purification.

\section{Conclusion}

The research was conducted with the aim of identifying the relationship between the motivation of participation of marine leisure sports participants and psychological wellbeing, and the conclusions obtained through the research process are as follows.

First, the internal motivation of marine leisure sports participants was positively correlated with all factors of psychological well-being.

Second, external motivations and motiveless demonstrated positive correlations with beneficial interpersonal relationships, life purposes, individual growth, autonomy, self-acceptance..

Third, participation motivation of marine leisure sports participants were found to have beneficial influence on self-acceptance and positive individual growth. Internal and external motivation were shown to have positive effects on environmental dominance. External motivation and motiveless were found to have positive effects on personal growth and autonomy. The conclusion of the study show that participation motivation of marine leisure sports participants is an important factor that positively affects psychological well-being.

\section{References}

[1] Peng, Y., Kim, S. H., \& Lee, B. C. A Study on the relationship between Participation Motivation and Psychological Well-being of Sports for All Program Participants. The Korean Society of Sports Science. 
2018; 27(5): 121-132.

[2] So, J. S. The Relationship between the Flow Experience and Participation Adherence Behavior Intention according to the Participation Motivation of Extreme Sports Participants. Unpublished master's Dissertation, Andong University; 2009.

[3] Choi, E. A., \& Kim, M. G. The Influence of Active Synier's Participation in Sports on Leisure Satisfaction and Quality of Life. The Korea Journal of Sport. 2019; 17(3): 297-307.

[4] Park, H. S., Choi, J. W., \& Choi, J. I. The Effects of Participation Motivation and Training Environment on the Exercise Adherence Intention of Taekwondo Trainees. The Korea Journal of Sport. 2019; 17(3): 651-660.

[5] Kim, D. J. The Influence of Participation Motivation for Lifetime Sports on Participation Satisfaction and Continuous Exercise Performance. The Korea Journal of Sport. 2019; 17(3): 245-253.

[6] Lee, G. C. The Relationship of Participant Motivation, Physical Self-concept, University Life Satisfaction of the Leisure Sport on the University Students. Journal of Korea Academia-Industrial cooperation Society.2019; 20(12): 357-366.

[7] Lee, M. A., \& Lee, G. H. The Effect of Sport Commitment on Positive Psychological Capital and Psychological Wellbeing Moderated by Duration of Life Sports Participants. Journal of Sport and Leisure Studies. 2019; 76: 183-198.

[8] Kang, J. H., Kim, J. H., \& Koo, B. J. The relationship between Leisure Satisfaction, Psychological Wellbeing, Exercise Adherence to Students of the Education University. The Korean Journal of Elementary Physical Education. 2019; 25(1): 79-95.

[9] Kim, S. J. Relationship Between Leisure Satisfaction and Psychological Wellbeing of Leisure Sports Participating University Students. Korean journal of physical education. 2018; 57(2): 291-302.

[10] Lee, Y. C. The Effect of Entertainment Factor for Housewives' Dance Sports Participation on Psychological Well-being and Emotional Intelligence. Journal of Sport and Leisure Studies. 2017; 69: 295-307.

[11] Kim, W. G. A Study on the Relationship between Participation Motives, Participation Satisfaction and Psychological Well-being of Dance Sports Participants. Journal of Korean Society for Rhythmic Exercises. 2017; 10(2): 49-60.

[12] Jung, J. N., \& Oh, K. R. How Sports Tour Experience of Participants, in Shooting Sports, Affects Positive Psychological Capital and Psychological Wellbeing. Korean Society of Sports Science. 2016; 25(4): 431-443.

[13] Song, Y. K., Lee, E. Y., \& Jeon, Y. G. Associations between Participation in School Sport Clubs, SelfRated Health and Psychological Well-Being in a Representative Sample of South Korean Adolescents. Journal of Korean Physical Education Association for Girls and Women. 2016; 30(3): 41-56. 